\section{Genital hygiene behaviors and practices: A cross-sectional descriptive study among antenatal care attendees}

\author{
Patrick Martial Nkamedjie Pete, ${ }^{1}$ \\ Rodrigue Mabvouna Biguioh, ${ }^{2}$ \\ André Gael Bita Izacar, ${ }^{3}$ \\ Sali Ben Béchir Adogaye, ${ }^{2}$ \\ Cecile Nguemo ${ }^{4}$ \\ ${ }^{1}$ Institute for Research, Socio-economic \\ Development and Communication \\ (IRESCO), Yaoundé, Cameroon; \\ ${ }^{2}$ Faculty of Medicine and surgery, \\ University of Roma "Tor Vergata", \\ Roma, Italy; ${ }^{3}$ Eliabeth Graser's \\ Pediatric Aids Foundation (EGPAF), \\ Yaoundé, Cameroon; ${ }^{4}$ Lafe Sub \\ Divisional Hospital, Mifi Health District, \\ West Region, Cameroon
}

\begin{abstract}
The female genital tracts harbor a wide variety of microorganisms' knowns as microflora mostly constituted by lactobacilli, involved in the healthy state of the vagina without causing infection. Urinary tract infections (UTI) are frequent in pregnant women due to physiological and anatomical changes that occur during pregnancy. These infections can result to disabilities or serious health problems both for the mother and the new-born. Vaginal douching has been reported among risky practices associate with UTIs. However, this remains debatable and contradictory when other studies report the benefit effects of vaginal cleaning in infection prevention. The aim of this study was to assess pregnant women behaviors and practices regarding genital hygiene. This was a cross sectional descriptive study conducted on exhaustive sample of pregnant women coming for antenatal visits in Lafé Sub-divisional Hospital (SDH) and Baleng Catholic Health Center (BCHC) between 16 and 30 September 2013. Data were collected using a paper based standardized questionnaire directly self-administered after obtain a free consent. Overall, 80 pregnant women were enrolled. The majority of them had attended at least primary education $(97.5 \% ; \mathrm{n}=78 / 80)$ and many were lived in couple $(81.25 \%$; $\mathrm{n}=65 / 80$ ). Almost one on three participants identified antenatal consultation (ANC) as a key element to be taken into account by pregnant women. $70.1 \% \quad(n=56 / 80)$ of women declared wearing undergarments in cotton. Regarding the daily vaginal douch-
\end{abstract}

ing behaviors, the majority $(76.3 \%$; $\mathrm{n}=61 / 80)$ of participants used the recommended gynecological measure, while the remaining use self-prescribed measures. Both genital parts (vulva area and vagina) were cleaned and use of water was mostly cited $(63.8 \% ; n=51 / 80)$. Almost one participant on four $(n=29 / 80)$ use antiseptic solutions for genital cleaning. Antiseptic solutions were associated with water in $34.5 \%$ of cases $(n=10 / 29)$, and in $65.5 \%(n=19 / 29)$ of cases it was used only for the vagina. Our findings suggest that knowledge and genital hygiene cleaning practices are acceptable among our study population. Risky practices such as use of antiseptic solutions and synthetic underwear's were reported. Skills of health care providers on good hygiene practices for pregnant should be improved and community-based communication strategies need to be implemented to reach all women of child bearing age.

\section{Introduction}

The female genital tracts harbor a wide variety of microorganisms' knowns as microflora, ${ }^{1}$ which are commensals species of the vaginal biota mostly constituted by lactobacilli, ${ }^{2}$ involved with other urogenital microbiota in the healthy state of the vagina without causing infection. ${ }^{2-4}$ However, they may become pathogenic in case of disorder in the normal microflora. ${ }^{5}$ Urinary tract infections (UTI) are frequent during pregnancy. ${ }^{6,7}$ From a physiopatholological point of view, UTIs occur when there is a shift in the normal flora dominated by lactobacilli to coliform uropathogens. ${ }^{8}$ UTIs can result to disabilitaties, ${ }^{9}$ and serious health problems for the mother and the new-born, ${ }^{10,11}$ such as pyelonephritis, low birth weight, premature labor, preterm birth, hypertension, preeclampsia, and increased incidence of perinatal death. ${ }^{12-19}$

Several studies have reported physiological changes that occur during pregnancy as factors decreasing the ability of the lower urinary tract to resist invading bacteria..$^{20-25}$ These factors, including anatomical factors, ${ }^{26,27}$ altered vaginal biota, ${ }^{8}$ genetic factors, ${ }^{28-31}$ diabetes, ${ }^{32,33}$ dysfunctional voiding, ${ }^{34}$ coupled to poor vaginal hygiene and not wearing proper underclothes contribute to the development of urinary tract infections (UTI) in women. ${ }^{35}$ For these raisons, some pregnant women have recourse to several self-prescribed preventive measures such as vaginal douching (intravaginal irrigation with water or other fluids). ${ }^{36-39}$ This old practice is mostly prevalent among black women compared to white women, ${ }^{40-42}$ and sometimes include
Correspondence: Patrick Martial Pete Nkamedjie, Institute for Research, Socio-economic Development and Communication (IRESCO), Yaoundé, Cameroon.

Tel.: +243993301061.

E-mail: patricknkamedjie@yahoo.com

Key words: genitalia hygiene, pregnancy, KAP, maternal and child health.

Acknowledgments: the authors gratefully acknowledge all the women who volunteered for this study. We extend our gratitude to the various heads of the Lafe Sub-divisional Hospital and Baleng Catholic Health Center for granting authorization to access the health centers. Special thanks to the data collectors for their involvement in the present study

Contributions: NPPM and MBR participated in the design of the study, data analysis, interpretation and drafted the first manuscript. BIAG, SBBA participated in data interpretation and manuscript revision. NC conceived of the study, participated in its design and coordination of data collection. All authors read and approved the different study steps and the final manuscript.

Conflict of interests: the authors declare no potential conflict of interests.

Funding: none

Received for publication: 31 July 2017.

Accepted for publication: 10 July 2018.

This work is licensed under a Creative Commons Attribution NonCommercial 4.0 License (CC BY-NC 4.0).

CCopyright P. Nkamedjie et al., 2019

Licensee PAGEPress, Italy

Journal of Public Health in Africa 2019; 10:746 doi:10.4081/jphia.2019.746

using of decoctions for other purposes such as to enhance sexual pleasure. ${ }^{43,44}$

The prevalence and risk factors of UTI in women were already investigated. It has been suggested that vaginal douching may disrupt the normal vaginal milieu, inducing changing in microflora from non-pathogenic to pathogenic, ${ }^{45-48}$ associated with a resistance decrease to infections of the vaginal tissue. ${ }^{49-52}$ However, the relevant of these findings remain debatable, incomplete, contradictory or difficult to understand. In fact, besides several studies reporting vaginal douching associated with various adverse gynecologic and reproductive outcomes, ${ }^{53-59}$ other authors have shown the hygiene effects on vaginal infection prevention including sexual transmitted infections (STIs). ${ }^{60-63}$ 
This study therefore was carried out to assess pregnant women behaviors regarding vaginal douching and their genital cleaning practices, including douching techniques, indications that might influence vaginal douching health outcome.

\section{Materials and Methods \\ Study design and targeted population}

This was a cross sectional descriptive study conducted on exhaustive sample of pregnant women recruited from Lafé Subdivisional Hospital (SDH) and Baleng Catholic Health Center (BCHC) between 16 and 30 September 2013. These health facilities are located in Lafe health area, Mifi health district found in western Cameroon. All pregnant women of at least 2 months of pregnancy visiting either health facility for antenatal care were enrolled on a daily basis. Women were approached as they arrive to study sites and recruitment was done progressively till total number of participants was obtained.

\section{Data collection procedure}

Health workers at the targeted health facilities were recruited and trained on interview process and data reporting. The targeted population was approached as they arrived the study sites. Following consultation or admission of a pregnant woman, a clear and thorough explanation of the objectives and nature of the study was provided and the participant was invited to take part in the study. After a signed informed consent was obtained, socio-demographic characteristics, awareness of hygienic practices, and data on pregnant women dressing and underwear were collected from respondents using a paper based standardized questionnaire directly self-administered under supervision of the interviewers. The questionnaire also included questions about behaviors of vaginal douching and the use of using of antiseptic solution.

\section{Analytical approach}

Data were analyzed using Epi-info software version 3.5.3 (CDC, Atlanta, GA, USA). Variables on hygiene measures knowledge, dressing and underwear habits, vaginal douching habits and the use of antiseptic agents were stratified by age (years) and educational level. Descriptive statistics of variable frequencies and proportions was applied. Microsoft office Excel and Word 2007 were used to obtain tables and graphics.

\section{Ethical considerations}

This study was carried out in view of obtaining the professional Bachelors of Sciences in nursing. Approval of the study were gotten from the academic institution (INSAM, Bafoussam, Cameroon) and the Lafe Sub-divisional hospital.

\section{Results}

\section{Socio-demographic characteristics of participants}

Overall, 80 pregnant women were enrolled in the study. Table 1 resumes the socio-demographic characteristics of the study population. The majority of participants had attended at least primary education $(97.5 \% ; n=78 / 80)$. Most respondents lived in couple $(81.25 \% ; n=65 / 80)$ with husband $(43.75 ; n=35 / 80)$ or domestic partner $(37.5 \% ; n=30 / 80)$ and had a professional occupation $(66.25 ; \mathrm{n}=53 / 80)$.

\section{Knowledge on hygiene measures of participants}

The graph below shows various perceptions of women regarding the notion of pregnant woman hygiene. Almost one on two participants identified antenatal consultation (ANC) as a key element to be taken into account by pregnant women. However, only a minority $(8.8 \% ; n=7 / 80)$ recognized a balance diet as a component of hygiene for them. It was interesting finding that no positive answer was given regarding tobacco consumption during pregnancy.

\section{Pregnant women dressing and underwear}

Most participants interviewed $(85.0 \%$; $\mathrm{n}=68 / 80$ ) consented with the fact that gown were more comfortable and recommended for women during gestational periods. Data also shows that, respondents adhered to the idea that pregnant women underwear must be made up of cotton and synthetic fibers; most of which showed preference for cotton (70.1\%; $n=56 / 80)$. However, only few mentioned underwear materials other than the 2 cited above.

\section{Vaginal douching behaviors of participants}

We investigated on the daily vaginal douching behaviors of the study participants. Our results revealed that, the majority $(76.3 \% ; n=61 / 80)$ of participants applied the recommended gynecological methods, while the remaining use self-prescribed measures $(18.8 \% ; n=15 / 80)$, or self-prescribed combined with recommended gynecological methods $(5 \% ; n=4 / 80)$. Although health facilities $(30.0 \% ; \mathrm{n}=24 / 80)$ and schools $(16.3 \% ; n=13 / 80)$ were cites among places where women received information on proper genital hygiene practices, the majority of participants $(53.8 \%$; $n=43 / 80)$, declared receiving this information from a family member.

Our research findings also suggest that $93.7 \% \quad(n=75 / 80)$ of participants interviewed were aware of the fact that all pregnant women should practice good genital hygiene that is recommended throughout the entire gestational period and not only at the final stage of pregnancy or following the outcome of an illness as mentioned by $3.8 \%(n=3 / 80)$ and $2.5 \%(n=2 / 80)$ respectively.

\section{Body and genital cleaning practices of participants}

As a component of personal hygiene, $37.3 \% \quad(n=30 / 80)$ of participants chosen bathing (soaking the whole body in water), while $35.8 \%(27 / 80)$ preferred a shower as recommended in pregnant women. The other participants $(26.9 \% ; n=23 / 80)$ practiced the both methods cited above.

Regarding genital cleaning practices, as shown in Table 2, both genital parts (vulva area and vagina) are cleaned simultaneously $(66.3 \% ; n=53 / 80)$. Use of non-irritating agent (water) for genital cleaning was mostly cited $(63.8 \% ; n=51 / 80)$ among participants. Almost one participant on four $(n=29 / 80)$ used antiseptic solutions for genital cleaning (vulva area and vagina). Antiseptic solutions were associated with water in $34.5 \%$ of cases $(n=10 / 29)$, and in

Table 1. Socio-demographic characteristics of the study population.

\begin{tabular}{lcc}
$\mathbf{N}=80$ & Frequency & $\begin{array}{c}\text { Proportion } \\
(\%)\end{array}$ \\
& & \\
Age (years) & & \\
$15-25$ & 37 & 46.2 \\
$26-35$ & 32 & 40.0 \\
$36-45$ & 11 & 13.8 \\
Educational level & & \\
None & 2 & 2.4 \\
Primary & 27 & 33.8 \\
Secondary & 47 & 58.8 \\
University & 4 & 5.0 \\
\hline Participants marital status & & \\
$\quad$ Single & 15 & 18.9 \\
Cohabitation & 30 & 37.8 \\
$\quad$ Married & 35 & 43.8 \\
Professional occupation & & \\
Farmer & 26 & 32.5 \\
Housewife & 27 & 33.8 \\
Government worker & 7 & 8.8 \\
Private sector & 8 & 11.3 \\
Other & 12 & 15.0 \\
\hline
\end{tabular}


$65.5 \%(n=19 / 29)$ of cases it was used only for the vagina.

\section{Discussion}

According to the 2011 Cameroonian Demographic Health Survey, maternal mortality has significantly increased over 2004 - 2011 period compared to 1991 - 1998 period. ${ }^{62}$ Maternal deaths account for $22 \%$ of total women aged 15 - 49 years deaths recorded in the country. ${ }^{62}$ Despite these trends and the fact that health practices during pregnancy is an important factor of perinatal and long term maternal and child health, ${ }^{11}$ few researches has been carried out on this topic in Cameroon.

Our research aimed at highlighting genital hygiene including personal hygiene behaviors and practices among pregnant women recruited in some selected health facilities. Antenatal care and diet are key components that need to be followed up and monitored during pregnancy. Few study participants $(37.5 \% ; n=30 / 80)$ and $(8.8 \%$; $\mathrm{n}=7 / 80$ ) respectively could highlight this fact indicating the need to strengthen sanitary and nutritional educational activities during antenatal visits.

Scholes and collaborators (2000), in their study on the risk factors for recurrent urinary tract infection in young women cited wearing tight undergarments among factors predisposing women to recurrent UTIs. ${ }^{35}$ In this study, close to three quarters $(70.1 \% ; n=56 / 80)$ of participants declared wearing ample undergarments in cotton indicating the good integration and practice of health promotion advice provided to women during antenatal visits.

Taking a bath by soaking the whole body in water could have potential genital adverse effects if the water used is of poor quality, and it is important to know the

Table 2. Types of genital part cleaned according to agents used.

\begin{tabular}{lcc} 
Ne80 & Frequency & $\begin{array}{c}\text { Proportion } \\
(\%)\end{array}$ \\
& & \\
Vulva area & 22 & 27.5 \\
$\quad$ Water & 0 & 0 \\
Antiseptic & 0 \\
Water and antiseptic & 0 & \\
Vaginal & & 0 \\
Water & 0 & 0 \\
Antiseptic & 0 & 6.3 \\
$\quad$ Water and antiseptic & 5 & \\
Vulva area and vaginal & & 35.7 \\
$\quad$ Water & 29 & 23.8 \\
Antiseptic & 19 & 6.3 \\
$\quad$ Water and antiseptic & 5 & \\
\hline
\end{tabular}

extent of this practice. Overall, three different bathing habits were found among participants: shower, soaking the whole body in water and the combination of both. Further studies should be conducted to identify risky types of bathing and their consequences. Vaginal douching practices vary according to cultural factors and can be transmitted from one generation to the other. This was observed in the current study where the majority of participants $(53.8 \%$; $n=43 / 80)$ declared receive information on genital hygiene from a family member. As noted in previous studies from Africa, black women believe the vagina contains germs; raison for the widespread practice of douching. ${ }^{40-42}$ Other studies reported vaginal douching and use of antiseptic agents as a major factor in the outcome of reproductive and gynecologic health problems. ${ }^{45-48}$ In this study, use of non-irritating agent for genital cleaning was mostly cited, but only for vulva cleaning $(27.5 \% ; n=22 / 80)$. Antiseptic solutions or associated with water were preferred for vaginal cleaning, suggesting that women perceive this genital part as most susceptible for pathogenic germs growth, and thus, requires more attention. But this is a risky practice for the vaginal microflora as reported by other authors. ${ }^{46,47}$

\section{Conclusions}

Knowledge and genital hygiene cleaning practices especially for pregnant women are quite acceptable in our study population. However, the use of antiseptic solutions and synthetic underwear's are risky practices that can have an outcome on the incidence of infections in gestational women and therefore constitute a danger for the fetus and newborn. Even if globally the results revealed an acceptable integration and application of health promotion advices, skills of health care providers on good hygiene practices for pregnant should be more improved mostly regarding genital cleaning. Community-based communication strategies need also to be implemented to reach all women of child bearing age.

\section{References}

1. Larsen B. Vaginal flora in health and disease. Clin Obstetrics Gynaecol 1993;36:107-21.

2. Aroutcheva A, Gariti D, Simon M, et al. Defense factors of vaginal lactobacilli. Am J Obstet Gynecol 2001;185:375-9.

3. Hilier SL. Laboratory diagnosis of yeast vaginitis. In: Horowitz B, Mardh PA, eds. Vaginitis and Vaginosis. New York, NY: Wiley-Liss Inc; 1991. pp 121-124.

4. Schwebke JR. Vaginal infections. In: Goldman MB. Hatch MC, eds. Women $\&$ health. San Diego: Academic Press; 2000. pp 352-360.

5. Monif GR, Thompson JL, Stephens $\mathrm{HD}$, et al. Quantitative and qualitative effects of povidone-iodine liquid and gel on the aerobic and anaerobic flora of the female genital tract. Am J Obstet Gynecol 1980;137:432-8.

6. Yazici S, Demirsoy G. Urinary tract infection and genital hygiene in pregnancy. Turk Clin Obstet Gynecol 2009;19:241-8.

7. Olsen BE, Hinderaker SG, Lie RT, et al. The diagnosis of urinary tract infections among pregnant women in rural Tanzania; prevalences and correspondence between different diagnostic methods. Acta Obstet Gynecol Scand 2000;79:729-36.

8. Kirjavainen PV, Pautler S, Baroja ML, et al. Abnormal immunological profile and vaginal microbiota in women prone to urinary tract infections. Clin Vaccine Immunol 2009;16:29-36.

9. Rein DM, Kassler WJ, Irwin KL, Rabiee L. Direct Medical Cost of Pelvic Inflammatory Disease and Its Sequelae Decreasing, but Still Substantial. Obstet Gynecol 2000;95:397-402.

10. Hooton TM, Stamm WE. Urinary tract infections and asymptomatic bacteriuria in pregnancy. Up To Date 2007. From: http://obgyndo.com/resources/Rotating -Residents/intern-Uptodate-UTI-andasymptomatic-bacteriuria-in-pregnancy.pdf. Accessed Dec 2012.

11. Ahmed Al-Badr, Ghadeer Al-Shaikh. Recurrent Urinary Tract Infections Management in Women. Sultan Qaboos University Med J 2013;13:359-67.

12. Hillier SL, Nugent RP, Eschenbach DA, et al. Association between bacterial vaginosis and preterm delivery of a low-birth-weight infant. N Engl J Med 1995;333:1737-42.

13. Fiscella K, Franks P, Kendrick JS et al. The risk of low birth weight associated with vaginal douching. Obstet Gynecol 1998;92:913-7.

14. Holst E, Goffeng AR, Andersch B. Bacterial vaginosis and vaginal microorganisms in idiopathic premature labor and association with pregnancy outcome. J Clin Microbiol 1994;32: 176-86.

15. Hay PE, Lamont RF, Taylor-Robinson $\mathrm{D}$ et al. Abnormal bacterial colonisation of the genital tract and subsequent preterm delivery and late miscarriage. BMJ 1994;308:295-8. 
16. Meis PJ, Goldenberg RL, Mercer B, et al. The preterm prediction study: significance of vaginal infections. Am J Obstet Gynecol 1995;173:1231-5

17. Faro S, Martens M, Maccato M, et al. Vaginal flora and pelvic inflammatory disease. Am J Obstet Gynecol 1993;169:470-4

18. Soper DE, Brockwell NJ, Dalton HP, et al. Observations concerning the microbial etiology of acute salpingitis (with discussion). Am J Obstet Gynecol 1994;170:1008-17.

19. Sweet RL. Role of bacterial vaginosis in pelvic inflammatory disease. Clin Infect Dis 1995;20:S271-5.

20. Delzell JE Jr, Lefevre ML. Urinary tract infections during pregnancy. Am Fam Physician 2000;61:713-21.

21. Haylen BT, Lee J, Husselbee S, et al. Recurrent urinary tract infections in women with symptoms of pelvic floor dysfunction. Int Urogynecol J 2009; 20:837-42.

22. Patterson TF, Andriole VT. Detection, significance, and therapy of bacteriuria in pregnancy. Update in the managed health care era. Infect Dis Clin North Am 1997;11:593-608.

23. Hill JB, Sheffield JS, McIntire DD, Wendel GD Jr. Acute pyelonephritis in pregnancy. Obstet Gynecol 2005; 105:18-23.

24. Golan A, Wexler S, Amit A, et al. Asymptomatic bacteriuria in normal and high-risk pregnancy. Eur J Obstet Gynecol Reprod Biol 1989;33:101-8.

25. Krcmery S, Hromec J, Demesova D. Treatment of lower urinary tract Infection in pregnancy. Int J Antimicrob Agents 2001;17:279-82.

26. Yamamoto $\mathrm{S}$, Tsukamoto $\mathrm{T}$, Terai A, et al. Genetic evidence supporting the fecal-perineal-urethral hypothesis in cystitis caused by Escherichia coli. J Urol 1997;157:1127-9.

27. Hooton TM, Stapleton AE, Roberts PL, et al. Perineal anatomy and urine-voiding characteristics of young women with and without recurrent urinary tract infections. Clin Infect Dis 1999;29:1600-1.

28. Raz R. Postmenopausal women with recurrent UTI. Int J Antimicrob Agents 2001;17:269-71.

29. Hooton TM, Scholes D, Stapleton AE et al. A prospective study of asymptomatic bacteriuria in sexually active young women. N Engl J Med 2000;343:992-7.

30. Hawn TR, Scholes D, Wang $\mathrm{H}$ et al. Genetic variation of the human urinary tract innate immune response and asymptomatic bacteriuria in women. PLoS One 2009;4:e8300.
31. Hawn TR, Scholes D, Li SS et al. Tolllike receptor polymorphisms and susceptibility to urinary tract infections in adult women. PLoS One 2009;4:e5990.

32. Geerlings SE, Stolk RP, Camps MJ, et al. Asymptomatic bacteriuria may be considered a complication in women with diabetes. Diabetes Care 2000;23: 744-9.

33. Geerlings SE, Stolk RP, Camps MJ et al. Risk factors for symptomatic urinary tract infection in women with diabetes. Diabetes Care 2000;23:1737-41.

34. Yagci S, Kibar Y, Akay O, et al. The effect of biofeedback treatment on voiding and urodynamic parameters in children with voiding dysfunction. J Urol 2005;174:1994-7.

35. Scholes D, Hooton TM, Roberts PL, et al. Risk factors for recurrent urinary tract infection in young women. J Infect Dis 2000; $182: 1177-82$.

36. Rothman KJ, Funch DP, Alfredson T, et al. Randomized field trial of vaginal douching, pelvic inflammatory disease and pregnancy. Epidemiology 2003; $14: 340$

37. Rosenberg MJ, Phillips RS, Holmes MD. Vaginal douching. Who and why? J Reprod Med 1991;36:753-8

38. Rosenberg MJ, Phillips RS. Does douching promote ascending infection? J Reprod Med 1992;37:930-8

39. Foch B, Mc Daniel N, Chacko M. Vaginal douching in adolescents attending a family planning clinic. J Pediatr Adolesc Gynecol 2000;13:92.

40. Sutton MY, Bruce C, Sternberg MR, et al. Prevalence and correlates of vaginal douching among women in the United States, 2001-2002. National STD Prevention Conference 2006.

41. Foch BJ, Mc Daniel ND, Chacko MR. Racial differences in vaginal douching knowledge, attitude, and practices among sexually active adolescents. J Pediatr Adolesc Gynecol 2001;14:2933.

42. Funkhouser E, Pulley L, Lueschen G, et al. Douching beliefs and practices among black and white women. J Womens Health Gend Based Med 2002;11:29-37.

43. Brown RC, Brown JE, Ayowa OB. Vaginal inflammation in Africa. N Engl J Med 1992;327:572.

44. Irwin K, Mibandumba N, Mbuyi K et al. More on vaginal inflammation in Africa. N Engl J Med 1993;328:888-9.

45. Onderdonk AB, Delaney ML, Hinkson PL, DuBois AM. Quantitative and qualitative effects of douche preparations on vaginal microflora. Obstet Gynecol 1992;80:333-8.
46. Monif GR, Thompson JL, Stephens HD, Baer H. Quantitative and qualitative effects of povidoneiodine liquid and gel on the aerobic and anaerobic flora of the female genital tract. Am J Obstet Gynecol 1980;137:432-8.

47. Pavlova SI, Tao L. In vitro inhibition of commercial douche products against vaginal microflora. Infect Dis Obstet Gynecol 2000;8:99-104.

48. Zhang J, Thomas AG, Leybovich E. Vaginal douching and adverse health effects: a meta-analysis. Am J Public Health 1997;87:1207-11.

49. Martino JL, Vermund SH. Vaginal douching: Evidence for risks or benefits to women's health. Epidemiol Rev 2002;24:109.

50. Holzman C, Leventhal JM, Qiu H et al. Factors linked to bacterial vaginosis in non-pregnant women. Am J Public Health 2001;91:1664-70

51. Hutchinson KB, Kip KE, Ness RB. Gynecologic Infection Follow-Through (GIFT) Investigators. Vaginal douching and development of bacterial vaginosis among women with normal and abnormal vaginal microflora. Sex Transm Dis 2007;34:671-5.

52. Ness RB, Hillier SL, Richter HE et al. Douching in relation to bacterial vaginosis, lactobacilli, and facultative bacteria in the vagina. Obstet Gynecol 2002;100:765.

53. Scholes D, Stergachis A, Ichikawa LE, et al. Vaginal douching as a risk factor for cervical Chlamydia trachomatis infection. Obstet Gynecol 1998;91:9937.

54. Scholes D, Daling JR, Stergachis A et al. Vaginal douching as a risk factor for acute pelvic inflammatory disease. Obstet Gynecol 1993;81:601-6.

55. Wolner-Hanssen P, Eschenbach DA, Paavonen J, et al. Association between vaginal douching and acute pelvic inflammatory disease. JAMA 1990;263:1936-41.

56. Chow WH, Daling JR, Weiss NS, et al. Vaginal douching as a potential risk factor for tubal ectopic pregnancy. Am J Obstet Gynecol 1985;153:727-9.

57. Daling JR, Weiss NS, Schwartz SM, et al. Vaginal douching and the risk of tubal pregnancy. Epidemiology (Cambridge, Mass) 1991;2:40-8.

58. McClelland RS, Lavreys L, Hassan WM, et al. Vaginal washing and increased risk of HIV-1 acquisition among African women: a 10-year prospective study. AIDS 2006;20:26973.

59. Bruce FC, Fiscella K, Kendrick JS. Vaginal douching and preterm birth: an 
intriguing hypothesis. Med Hypotheses 2000;54:448-52.

60. Jenny LM, Sten HV. Vaginal Douching: Evidence for Risks or Benefits to Women's Health. Epidemiol Res 2002;24:109-24.

61. Sunay D, Kaya E, Ergun Y. Vaginal Douching Behavior of Women and
Relationship among Vaginal Douching and Vaginal Discharge and Demographic Factors. J Turk Soc Obstet Gynecol 2011;8:264-71.

62. Amiri FN, Rooshan MH, Ahmady MH, Soliamani MJ. Hygiene practices and sexual activity associated with urinary tract infection in pregnant women. East
Mediterr Health J 2009;15:104-10.

63. Institut National de la Statistique (INS), Cameroun and ICF International. Enquête Démographique et de Santé et à Indicateurs Multiples (EDS-MICS) 2011. Available from: http://dhsprogram.com/pubs/pdf/FR260/FR260.pdf. Accessed 13 January 2016. 